\title{
ANNOUNCEMENT \\ Conference on the \\ Neural and Developmental Bases of Spatial Orientation
}

\author{
November 15-18, 1979 \\ Teachers College, Columbia University, New York, New York
}

British and American investigators from the fields of developmental, environmental, and physiological psychology, clinical neurology, and neurophysiology will present recent research on spatial orientation in normal and special children, brain-damaged adults, and nonhuman animals.

For information write: Professor A. M. Gentile, Spatial Orientation Conference, Box 142, Teachers College, Columbia University, 525 West 120th Street, New York, New York 10027. Phone: (212) 678-3336.

\section{ANNOUNCEMENT \\ Formation of The Association for Chemoreception Sciences (AChemS)}

The Association for Chemoreception Sciences (AChemS) has been organized as a professional, interdisciplinary society to foster communication among anatomists, biologists, chemists, behavioral scientists, clinicians, etc., who are concerned with any aspect of the chemical sciences.

The first meeting held in Sarasota, Florida, on April 23-26, 1979, attracted 173 participants. In addition to over 70 poster papers, 30 oral presentations were given under the headings: (1) biological origins of odors, (2) clinical disorders of taste, (3) selection of food and regulation of intake, (4) creation of new chemosensory products, (5) aquatic chemoreception, (6) insect chemoreception, and (7) central nervous system processes in gustation and olfaction. Dr. Vincent G. Dethier (University of Massachusetts) delivered the Givaudan Lecture, which he entitled: "The odor of sanctity and the taste of sin."

Chief organizer of the first meeting was Maxwell M. Mozell (SUNY-Syracuse), who was elected Executive Chairman of the new Association. Thomas Getchell (Wayne State, Detroit) and Steven Price (Virginia Medical College, Richmond) are in charge of finances, and Rose Marie Pangborn (University of California, Davis) and Gary Beauchamp (Monell, Philadelphia) constitute the membership committee. Charlotte Mistretta (University of Michigan, Ann Arbor), Bernice Wenzel (UCLA), John Caprio (LSC, Baton Rouge), and William Cain (Pierce Foundation, New Haven) are planning the scientific program for the next meeting, scheduled for May 4-8, 1980, at the Sarasota Hyatt House.

Yearly dues are $\$ 20$ for professionals and $\$ 10$ for students. Scientists working in the broad field of chemoreception are invited to join the organization by sending name, area of interest, affiliation, address, telephone number, and a check for the 1980 dues (payable to AChemS) to R. M. Pangborn, Food Science \& Technology, University of California, Davis, California 95616 [phone: (916) 752-2168]. 